\section{Factores de riesgo para la prevalencia de infecciones de vías urinarias en mujeres de 18 a 34 años de edad}

\author{
Risk factors for the prevalence of urinary tract infections in \\ women 18 to 34 years of age
}

\section{Fatores de risco para prevalência de infecções do trato urinário em mulheres de 18 a 34 anos}

\author{
Roberth Olmedo Zambrano Santos \\ rzambranosantos@yahoo.es
}

Aida Monserrate Macías Alvia aidita.macias@hotmail.com Ronny Javier Reyes Baque renyrys@gmail.com

Recibido septiembre 2018 / Revisión octubre 2018 / Aceptado 1 de enero 2019

\section{RESUMEN}

Introducción: Las infecciones de vías urinarias, son consideradas como una de las infecciones de origen bacteriano más frecuente a nivel mundial. El incremento de casos de este tipo de infecciones en Ecuador, ha provocado problemas constantes debido a su alto crecimiento en diversos casos. Objetivo: Estudiar los factores de riesgo para la prevalencia de infecciones de vías urinarias en mujeres de 18 a 34 años de edad que asisten al centro de salud de Rocafuerte. Materiales y Método: La investigación es de carácter cuali-cuantitativo. Los instrumentos utilizados fueron la encuesta y la entrevista. La población seleccionada, está conformada por 393 mujeres, las cuales presentaron infección de vías urinarias en el año 2018 y fueron atendidas en el centro de salud de Rocafuerte. Resultados y discusión: Se determinó que la mayor parte de estas mujeres son de estado civil unión libre, el $57 \%$ de procedencia rural, también en una sumatoria el $80 \%$ de ellas desconocen lo que es una infección de vías urinarias, acuden seguido al centro de salud por presentar esta infección, el $51 \%$ presenta a menudo retenciones urinarias, el $63 \%$ conoce poco los síntomas, el $11 \%$ nunca ha escuchado una charla educativa sobre la infección y la mayoría considera que es muy buena la atención brindada y con esto ha mejorado en base a los cuidados de enfermería. Conclusión: En el centro de salud de Rocafuerte, las mujeres de 18 a 34 años de edad, poseen escasos conocimientos acerca de lo que es una infección de vías urinarias, ya sea por falta de interés, el nivel de educación, falta tiempo o por cualquier otro factor.

Palabras clave: infecciones urinarias; infecciones bacterianas; factores de riesgo; calidad de vida

\begin{abstract}
Introduction: Urinary tract infections are considered as one of the most frequent infections of bacterial origin worldwide. The increase in cases of this type of infections in Ecuador has caused constant problems due to its high growth in various cases. Objective: To study the risk factors for the prevalence of urinary tract infections in women 18 to 34 years of age attending the Rocafuerte health center. Materials and Method: The research is qualitative and quantitative. The instruments used were the survey and the interview. The selected population is made up of 393 women, who presented urinary tract infection in 2018 and were treated at the Rocafuerte health center. Results and discussion: It was determined that most of these women are of civil union free union, $57 \%$ of rural origin, also in a sum $80 \%$ of them do not know what a urinary tract infection is, come to the center of health due to this infection, $51 \%$ often have urinary retention, $63 \%$ know little about the symptoms, $11 \%$ have never heard an educational talk about the infection and most consider that the care provided is very good and with this It has improved based on nursing care. Conclusion: In the Rocafuerte health center, women between 18 and 34 years of age have little knowledge about what a urinary tract infection is, whether due to lack of interest, education level, lack of time or any other factor.
\end{abstract}

Key words: urinary tract infections; bacterial infections; risk factors; quality of life
RZ: Universidad Estatal del Sur de Manabí. Ecuador.

AM: Instituto Tecnológico Superior "Portoviejo. Ecuador. RR: Universidad Estatal del Sur de Manabí. 
RZ: Universidad Estatal del Sur de Manabí. Ecuador.

AM: Instituto Tecnológico Superior "Portoviejo. Ecuador.

RR: Universidad Estatal del Sur de Manabí.

\section{RESUMO}

Introdução: As infecções do trato urinário são consideradas uma das infecções mais frequentes de origem bacteriana em todo o mundo. $O$ aumento de casos desse tipo de infecção no Equador tem causado problemas constantes devido ao seu alto crescimento em vários casos. Objetivo: Estudar os fatores de risco para a prevalência de infecções do trato urinário em mulheres de 18 a 34 anos atendidas no centro de saúde Rocafuerte. Materiais e Método: A pesquisa é qualitativa e quantitativa. Os instrumentos utilizados foram a pesquisa e a entrevista. A população selecionada é composta por 393 mulheres, que apresentaram infecção do trato urinário em 2018 e foram atendidas no centro de saúde Rocafuerte. Resultados e discussão: Determinou-se que a maioria dessas mulheres é de união livre de união civil, $57 \%$ de origem rural, também em um total de $80 \%$ delas não sabem o que é uma infecção do trato urinário, chegam ao centro de saúde devido a essa infecção, $51 \%$ costumam ter retenção urinária, $63 \%$ sabem pouco sobre os sintomas, $11 \%$ nunca ouviram uma conversa educativa sobre a infecção e a maioria considera que o atendimento é muito bom e com isso Melhorou com base nos cuidados de enfermagem. Conclusão: No centro de saúde Rocafuerte, mulheres entre 18 e 34 anos de idade têm pouco conhecimento sobre o que é uma infecção do trato urinário, seja por falta de interesse, nível educacional, falta de tempo ou qualquer outro fator.

Palavras-chave: infecções do trato urinário; infecções bacterianas; fatores de risco; qualidade de vida

\section{INTRODUCCIÓN}

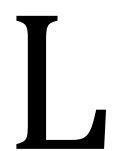
as infecciones de vías urinarias, son consideradas como una de las infecciones de origen bacteriano más frecuente a nivel mundial. En los hombres es muy común verla en edades adultas, por el contrario en las mujeres, se manifiestan en todas las edades, y con secuelas variables (1). El incremento de casos de infecciones de vías urinarias en Ecuador, Manabí y sobre todo en la ciudad de Rocafuerte en estos últimos años, ha provocado problemas constantes debido a su alto crecimiento en diversos casos.

El problema de la repercusión de esta infección presente en las mujeres que asisten al centro de salud de Rocafuerte, se puede determinar teniendo en cuenta dos puntos importantes: 1. Hay deficiencias de un autocuidado y, 2. Existen factores como las condiciones dónde viven, la educación, la higiene y los factores económicos que impiden una buena salud.

Las infecciones urinarias presentadas en mujeres, constituyen un problema de salud pública a nivel mundial ocupando el segundo lugar por debajo de las respiratorias. En los servicios de emergencia, representa la cuarta causa más común por la que las mujeres asisten a este servicio. La incidencia según el sexo, el género masculino tiene un porcentaje muy escaso, debido a que anatómicamente la uretra de los hombres tiene una longitud mayor, por el contrario, en las mujeres donde la uretra es corta, está en cercanía con la vagina y el recto, donde se puede encontrar diferentes gérmenes por lo que está muy susceptible a ser invadida por estos agentes (2).

Según el Ministerio de Salud Pública del Ecuador (MSP), la infección de vías urinarias es la existencia de gérmenes patógenos presentes en la orina por infección de la vejiga o el riñón. Existen datos que indican, que puede ser asintomática y puede variar de acuerdo al sitio de la infección (3). La infección urinaria se define como la invasión microbiana del aparato urinario, los cuales sobrepasan la capacidad de los mecanismos de defensa de la persona. Esta infección va a producir una reacción inflamatoria y alteraciones funcionales $y$ morfológicas, afectando tanto a hombres como mujeres en diferentes tipos de 
edades (4). Las infecciones de vías urinarias son una de las complicaciones más frecuentes durante el periodo de gestación, la forma más frecuente es la bacteriuria asintomática, su frecuencia varía entre el 5 al 7\% de las embarazadas, $\mathrm{y}$ en pacientes con bajos recursos económicos, estos porcentajes pueden multiplicarse hasta 5 veces más (1).

Durante el embarazo, se presentan varios cambios fisiológicos que van desde variaciones del $\mathrm{pH}$ hasta en el influjo de la progesterona, ambos disminuyen el tono del músculo liso uretral y la estasis del tracto urinario. También se suman anomalías como trastornos neurológicos, diabetes mellitus y la actividad sexual, ésta última favorece a la entrada de microorganismos al tracto genitourinario y su colonización. En el caso de los hombres, sólo se ha documentado la aparición de infección de vías urinarias cuando mantienen relaciones sexuales (5).

La infección está presente en todas las edades y se considera recurrente, si se producen dos o más episodios de pielonefritis aguda, un episodio de pielonefritis y uno o más de cistitis, o si es que presenta tres o más episodios de cistitis durante un año. Las infecciones de vías urinarias también se las considera atípica o complicadas cuando el paciente presenta sepsis, masa vesical o abdominal, flujo urinario escaso, aumento de la creatinina plasmática, si no presenta alguna señal de mejora o respuesta al tratamiento tras 48-72 horas de haberlo iniciado y por último, si es por un microorganismo diferente a Escherichia coli (6). Existe un alto rango de riesgo a contraer infección de vías urinarias durante el periodo de gestación, pero aquí influye bastante la paridad, la actividad sexual y la edad (1).
Una infección de vías urinarias se puede producir en cualquier parte del aparato urinario: en los riñones, en la uretra en la mujer o uréteres en los hombres y en la vejiga, siendo más común en estas dos últimas partes. Muchas veces, este tipo de infecciones, no siempre causa algún tipo de signo a primera instancia, pero cuando lo hace, pueden aparecer síntomas como polaquiuria, disuria y orina con aspecto turbio. También en casos frecuentes, hay hematuria, orina con olores fétidos y en las mujeres sobre todo hay dolores pélvicos. En cuanto a la clasificación de la infección de vías urinarias en la mujer se puede encontrar en base a su ubicación, las de vías bajas o inferiores, que comprende una cistitis y uretritis y las de vías altas o superiores, que comprende una pielonefritis aguda (7).

En las ITU bajas, solo va a afectar a la vejiga y la uretra, este tipo de infección se frecuentará en mujeres mayores a 2 años, comprenden síntomas locales como disuria, polaquiuria, micciones urgentes, orina turbia y malestares abdominales bajos. Mientras que en las altas, va a ser un tipo de infección que comprometerá severamente el parénquima renal (riñones), es la forma más grave de infección urinaria en niños. Los síntomas varían entre hipertermia, compromiso del estado general, dolor abdominal y lumbar, en ciertos casos, suele haber náuseas y vómitos (8).

El diagnostico de ITU está relacionado estrechamente con las manifestaciones clínicas y sus variables dependen de la edad, el sexo y las alteraciones anatómicas, urológicas y/o neurológicas que pueda presentar el individuo, por lo cual es importante que el índice de sospecha sea sumamente elevado especialmente en neonatos y lactantes febriles. La prueba 
diagnóstica esencial es el urocultivo y es imprescindible realizarla, antes de iniciar el tratamiento con antibióticos. Los recuentos bacterianos para dar positivo al urocultivo, varían de acuerdo a la manera en que se haya realizado la recolección de la orina (9).

El uso inadecuado, erróneo y empírico de los antibióticos en el tratamiento de la infección de vías urinarias, puede provocar fácilmente que las bacterias se vuelvan resistentes a las propias bacterias. Esto plantea un problema severo para el personal médico y sobre todo, la sensibilidad a los antimicrobianos y la prevalencia de uropatógenas, van a tener variación en cada centro de salud, hospital $\mathrm{y}$ ciudad. Investigaciones han comprobado, que la resistencia por parte de la E. Coli a las quinolonas, de manera específica a las ciprofloxacinas, se debe a anomalías del tracto urinario, la vejez, cateterismo urinario y tratamiento previo con fluoroquinolonas (10).

El objetivo general de la investigación es estudiar los factores de riesgo para la prevalencia de infecciones de vías urinarias en mujeres de 18 a 34 años de edad que asisten al centro de salud de Rocafuerte.

La cuidad de Rocafuerte cuenta con 33.376 habitantes de los cuales, 14 mil son mujeres, según el INEC (Instituto Nacional de Estadística y Censos). En el año 2018, en el centro de salud fueron atendidas más de 6 mil mujeres y 393 de ellas acudieron a consulta médica por presentar infecciones de vías urinarias. La muestra con la que se va a trabajar, son 90 mujeres de 18 a 34 años de edad, que presentaron infección de vías urinarias en el año 2018. Estos datos fueron filtrados mediante la
Plataforma de registro de atención en salud (PRAS), la cual fue facilitada por el área de estadística del centro de salud.

\section{MATERIALES Y MÉTODOS}

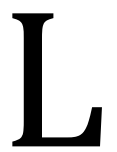
a investigación es de carácter cualicuantitativo. Los instrumentos utilizados fueron la encuesta y la entrevista. La población seleccionada para esta investigación, está conformada por 393 mujeres, las cuales presentaron infección de vías urinarias en el año 2018 y fueron atendidas en el centro de salud de Rocafuerte. La muestra fue obtenida, filtrando datos de la plataforma de registro de atención en salud (PRAS), proporcionada por el área de estadística del centro de salud y corresponde a 90 mujeres entre 18 y 34 años de edad.

El criterio de inclusión, fueron mujeres de 18 a 34 años de edad, que acudieron por presentar infecciones de vías urinarias durante el año 2018. Los criterios de exclusión fueron mujeres en estado de gestación diagnosticadas con infección de vías urinarias, mujeres menores de 18 y mayores de 34 años. Por último, mujeres que no fueron diagnosticadas con infección de vías urinarias. La información fue procesada y tabulada en una hoja de Microsoft Excel y presentada en valores de frecuencia absoluta y porcentual.

Esta investigación se enmarcó en principios éticos, fue aprobada por el Comité de ética respectivo y utilizó, el consentimiento informado.

\section{RESULTADOS}

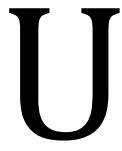
na vez aplicados los instrumentos de recolección de información, se procesaron los resultados, los cuales se reflejan a continuación: 
Tabla 1. Lugar de procedencia

\begin{tabular}{llc}
\hline Procedencia & Frecuencia & \% \\
\hline Urbano & 39 & 43 \\
Rural & 51 & 57 \\
Total & $\mathbf{9 0}$ & $\mathbf{1 0 0}$ \\
\hline
\end{tabular}

Fuente: instrumento aplicado

Según los datos obtenidos mediante la encuesta realizada, se puede observar en la tabla 1, que las infecciones de vías urinarias se presentan con mayor frecuencia en mujeres que viven en sitios rurales, reflejado en un 57\%. Esto se debe, a que las zonas rurales, no cuentan con todos los servicios básicos (el alcantarillado siendo el más importante) y en ciertas ocasiones, viven en condiciones de insalubridad, lo cual puede desencadenar fácilmente, una infección de vías urinarias.

Tabla 2. Frecuencia con la que asiste al centro de salud por presentar infección de vías urinarias

\begin{tabular}{lcc}
\hline & Frecuencia & \% \\
\hline Siempre & 43 & 47 \\
A veces & 25 & 28 \\
Rara vez & 17 & 19 \\
Nunca & 5 & 6 \\
Total & $\mathbf{9 0}$ & $\mathbf{1 0 0}$ \\
\hline
\end{tabular}

Fuente: instrumento aplicado

En la tabla 2, de las 90 mujeres encuestadas y en base a los datos obtenidos se observa, que la mayor parte de ellas, siempre acuden al centro de salud por presentar infección de vías urinarias, debido a factores como por ejemplo, un mal autocuidado, malos hábitos de higiene genital, condiciones insalubres en el sector donde viven, entre otros, provocando que la mayor parte de las mujeres entre 18 a 34 años de edad, acudan muy frecuentemente, al centro de salud por una infección urinaria.

Tabla 3. Sufre constantemente retenciones urinarias

\begin{tabular}{llc}
\hline & Frecuencia & $\mathbf{\%}$ \\
\hline Siempre & 23 & 26 \\
A veces & 46 & 51 \\
Rara vez & 11 & 12 \\
Nunca & 10 & 11 \\
Total & $\mathbf{9 0}$ & $\mathbf{1 0 0}$ \\
\hline
\end{tabular}

Fuente: instrumento aplicado 
En la tabla 3, se observa que existe un alto número de mujeres (51\%), que tienen varios episodios de retención urinaria, esto ocasiona vejigas grandes y perezosas con hipoactividad del músculo destructor, que llevarán a las mujeres a tener residuos pos-miccionales altos (más de $100 \mathrm{ml}$ ) y con ello, la posible infección de vías urinarias. Por otro lado, la falta de miccionar antes y después de tener relaciones sexuales, permite la colonización de bacterias, pues como se sabe, al orinar se va a producir el arrastre de estos agentes que pueden estar en la uretra de la mujer.

\section{DISCUSIÓN}

A proximadamente, un $10 \%$ de las mujeres presentan por lo menos 1 episodio de ITU no complicada al año y un $60 \%$, lo presenta durante su vida. El punto más alto de casos, se encuentra en mujeres con edades entre los 18 y 30 años sexualmente activas. También, esta entidad se frecuenta más, en mujeres con antecedentes familiares ya sea en mamás, hermanas o tías, las cuales tuvieron recurrentes episodios de cistitis. Y si nos referimos a su relación con su actividad sexual, se reporta que hay una relación del $75 \%$ al $90 \%$ de mujeres, que presentaron un episodio de infección de vías urinarias (11).

En las últimas décadas, las infecciones de vías urinarias han representado alrededor de siete millones de consultas médicas ambulatorias y alrededor de un millón de hospitalizaciones por cada año, lo que representa un costo al año de 1.6 millones de dólares en Estados Unidos. Estudios también han revelado, que la frecuencia de IT va de 53.067/100.000 mujeres y de 13.687/100.000 hombres. Existe una amplia diferencia dominada por las mujeres, pero esta va a disminuir, cuando lleguen a los 65 años. Aquí las cosas se invierten, debido a la retención e incontinencia urinaria y aumento de hiperplasia benigna de próstata (5).

Las mujeres latinoamericanas son más propensas a contraer una infección de vías urinarias, según lo confirmó el grupo corporativo de ginecólogos latinoamericanos mediante una encuesta piloto, cuyo objetivo fue, identificar las prácticas de higiene y aseo genital en mil mujeres que acudieron a la consulta en el año 2008, con la participación de 10 países, entre ellos: Colombia, Costa Rica, Ecuador, Guatemala, Honduras, México, Panamá, Perú, República Dominicana y Venezuela, demostrando que alrededor del $28 \%$ de mujeres, practicaban una técnica inadecuada de aseo genital, por lo que concluyeron, que es uno de los principales factores para que la cuarta parte de las mujeres latinas, suelan padecer infecciones urinarias. Por otro lado, es importante resaltar, que este proceso infeccioso, también se debe a la diversidad conduce a que las mujeres practiquen erróneamente, las normas de higiene y cambio de ropa interior (12).

Según datos estadísticos del Ministerio de Salud Pública en el año 2016, en Ecuador las infecciones de vías urinarias, se ubicaron en el cuarto lugar de las principales causas de morbilidad ambulatoria con 616.850 casos reportados, ocupando así un 5,44\% de todas las morbilidades. En Manabí, las infecciones de vías urinarias escalan 2 posiciones, ocupando el segundo lugar de causa de morbilidad ambulatoria, solo por debajo de casos de rinofaringitis aguda. Las infecciones de vías urinarias reportaron en ese año, más de 100 mil casos y más del $80 \%$ de estos, fueron en mujeres. Ahora bien, en la cuidad de Rocafuerte, el $7,56 \%$ de las causas de 
morbilidad la ocupan las infecciones de vías urinarias, logrando estar en el quinto lugar, con un poco más de mil trecientos casos (13).

Estos datos estadísticos son importantes al considerar los factores de riesgos para la prevalencia de ITU en mujeres, asociados a las condiciones de vida, de salubridad, a una frecuencia elevada de relaciones sexuales, a la adecuada higiene íntima de la mujer, al desconocimiento acerca de las infecciones urinarias.

De las 90 mujeres encuestadas, se obtienen datos que arrojan que el mayor porcentaje de ellas (47 mujeres) se encuentra en un estado civil de unión libre, esto debido a que la mayor parte de las encuestadas, son mujeres que provienen de sitios rurales $y$ no tienen como prioridad, casarse legal o eclesiásticamente por el momento y además, la mayoría de ellas, ya son sexualmente activas, lo que predispone en términos de riesgo, a una infección urinaria.

De acuerdo a los resultados obtenidos de las encuestas realizadas en el centro de salud de Rocafuerte, las mujeres de 18 a 34 años de edad, poseen escasos conocimientos acerca de lo que es una infección de vías urinarias, ya sea por falta de interés, el nivel de educación, falta tiempo o por cualquier otro factor. Son por estos motivos, que son muy recurrentes las infecciones de vías urinarias en el centro de salud.

\section{CONCLUSIONES}

S e concluye que los indicadores sociodemográficos influyen de una manera muy significativa en las mujeres con infección de vías urinarias, puesto que el $57 \%$ de ellas, habitan en sitios rurales donde no siempre tienen los servicios y saneamiento básicos y viven en condiciones de insalubridad. Además, el nivel educativo también influye, puesto que no le da la importancia que se merece la infección, ya que solo un $14 \%$ de las mujeres tienen una educación superior, el $52 \%$ de estado civil unión libre y el 56\% de las mujeres, realizan quehaceres domésticos. Se identificaron los factores de riesgo que provocan esta infección, tales como, el tener frecuentemente a la semana relaciones sexuales, el desconocimiento en identificar los signos y síntomas de IVU, un déficit en el consumo de agua para su higiene, retenciones urinarias frecuentes, además de esto, deficiencias en la técnica del aseo genital, el automedicarse cuando presenta síntomas de infección.

- Conflicto de intereses: Ninguno declarado por el autor.

- Fuente de financiamiento: Autofinanciado.

- Agradecimientos: Ninguno declarado por el autor

\section{REFERENCIAS BIBLIOGRÁFICAS}

1. Paucarima M. Incidencia de las infecciones de vías urinarias en embarazadas de 18 a 30 años. Universidad de Guayaquil. Facultad de Ciencias Médicas. Tesis de grado. 2013.Disponible en: http://repositorio.ug.edu.ec/bitstrea $\mathrm{m} /$ redug/1843/1/tesis\%20de\%0infe ccion $\% 20 \mathrm{de} \% 20$ vias\%20urinarias $\% 2$ 0-\%20maria\%20paucarima.pdf.

2. Tumbaco A, Martinez L. Factores de riesgo que influyen en la predisposición de infecciones urinarias en mujeres 15-49 años que acuden al subcentro Virgen del Carmen del cantón la libertad 20122013. Universidad Estatal Península de Santa Elena. Escuela de Ciencias de la Salud. Tesis de Grado. Ecuador. Disponible en: 
http://repositorio.upse.edu.ec/xmlui/ handle/46000/1003.

3. Ministerio de Salud Pública. Guía de Práctica Clínica (GPC). [Internet].; 2013. [Consultado $2017 \quad 7 \quad$ de diciembre]. Disponible en http://instituciones.msp.gob.ec /documentos/Guias/Guia_infeccion_v _u.pdf.

4. Diverger D, Valverde M, De la Cruz M, León T. Aspectos de la infección urinaria en el adulto. Revista Cubana de Medicina General Integral. 2013; 14(1).

5. Orrego C, Henao C, Cardona J. Prevalencia de infección urinaria. Acta med. colomb. 2014;39 (4). Disponible en:

http://www.scielo.org.co/pdf/amc/v 39n4/v39n4a08.pdf

6. Esparza GF, Motoa G, Robledo C, Villegas MV. Aspectos microbiológicos en el diagnóstico de infecciones del tracto urinario. Infectio, 2015;19(4):150-60.

7. Echevarría-Zárate J, Sarmiento E, Osores-Plenge F. Infección del tracto urinario y manejo antibiótico. Acta méd. peruana [Internet]. 2006 [citado 2018 Ene 26]; 2018;23(1):2631.Disponible en: http://www.scielo.org.pe/scielo.php? script=sci_arttext\&pid=S172859172006000100006\&lng=es.

8. Salas P, Barrera $P$, Gonzáles C, Zambrano P. Actualización en el diagnóstico y manejo de la infección urinaria en pediatría. Rev. chil. pediatr. 2012 Junio 2012; 83(3).

9. Moriyón J, Petit N, Coronel V, Ariza M. Infección urinaria en pediatría. Definición, epidemiología, patogenia, diagnóstico. AVPP. 2011; 74(1).

10. Castrillón J, et al. Etiología y perfil de resistencia antimicrobiana en pacientes con infección urinaria. Infectio [Internet] 2019; 23(1):45-51. Disponible en:http://www.scielo.org.co/pdf/inf/ v23n1/0123-9392-inf-23-0100045.pdf

11. Aparicio A, Rodríguez S, Tobar V, Carlos H. Frecuencia reportada de infección de vías urinarias no complicada en mujeres universitarias. Acta med. colomb. 2010;39(4):2. Disponible en: http://www.scielo.org.co/pdf/amc/v 39n4/v39n4a08.pdf

12. Cuevas A, Cuauthemoc C, Hernández I. Resultados de una encuesta epidemiológica de hábitos de higiene íntima en mujeres latinoamericanas. Rev. obste. ginecol. Venezuela ; 2011;71(1): 21-27

13. Ministerio de Salud Pública. public.tableau. [Internet].; 2016. [Consultado 201819 de enero]. Disponible en https://public.tableau.com/profile/da rwin5248\#!/vizhome/Perfildemorbili dadambulatoria2016/Men?publish=y es 